\title{
TECNOLOGIAS NA EDUCAÇÃO: O ENSINO HÍBRIDO ENQUANTO POSSIBILIDADE METODOLÓGICA
}

\author{
TECHNOLOGIES IN EDUCATION: HYBRID EDUCATION AS A \\ METHODOLOGICAL POSSIBILITY
}

\author{
TECNOLOGÍAS EN LA EDUCACIÓN: LA ENSEÑANZA HÍBRIDA EN CUANTO \\ POSIBILIDAD METODOLÓGICA
}

\author{
Jéssica Freitas Avrella ${ }^{1}$, Elisabete Cerutti ${ }^{2}$
}

\begin{abstract}
RESUMO: O presente trabalho, de cunho bibliográfico, objetiva abordar as mudanças geradas pelas inovações tecnológicas no âmbito educacional, destacando os principais benefícios trazidos pelas TDICS - tecnologias digitais de informação e comunicação, de que forma trabalhá-las em sala de aula e reflexões sobre os principais desafios desta inserção. Enquanto possibilidade metodológica, discorremos sobre o Ensino Híbrido, que visa unir o melhor da aula tradicional com algum tipo de tecnologia, ressaltando de que forma ele pode ser inserido no contexto escolar gradativamente, respeitando o tempo das pessoas envolvidas neste processo. Assim, pretendemos oferecer subsídios para que os professores tenham condições de levar inovações e tecnologias para o ambiente escolar, objetivando melhorias na qualidade do processo de ensino e de aprendizagem.
\end{abstract}

Palavras-chave: Inovações tecnológicas. Ensino Híbrido. Sala de aula.

\begin{abstract}
This paper aims to present reflections about the technological innovations in the educational field, highlighting the main benefits of the TDICS - digital communication and information technologies, how to work them in the classroom and reflections on the main challenges of this insertion. As a methodological possibility, we talk about Hybrid Teaching, which aims to unite the best of the traditional classroom with some kind of technology, highlighting how it can be inserted in the school context gradually, with attention to the time of the people involved in this process. Thus, we intend to offer subsidies for teachers to be able to bring innovations and technologies to the school environment, aiming at improvements in the quality of the teaching and learning process.
\end{abstract}

Keywords: Technological innovations. Hybrid teaching. Classroom.

\section{RESUMEN}

El presente trabajo, de cuño bibliográfico, objetiva abordar los cambios generados por las innovaciones tecnológicas en el ámbito educativo, destacando los principales beneficios aportados por las TDICS tecnologías digitales de información y comunicación, de qué forma trabajarlas en el aula y reflexiones sobre los principales retos de esta inserción. En cuanto posibilidad metodológica, discordamos sobre la Enseñanza Híbrida, que pretende unir lo mejor de la clase tradicional con algún tipo de tecnología, resaltando de qué forma puede ser insertado en el contexto escolar gradualmente, respetando el tiempo de las personas involucradas en este proceso. Así, pretendemos ofrecer subsidios para que los profesores

\footnotetext{
${ }^{1}$ Mestre em Educação pelo PPGEDU/ URI-FW.

${ }^{2}$ Docente do PPGEDU/ URI-FW. Doutora em Educação pela PUC-RS.
}

\begin{tabular}{c|c|c|c}
\hline Rev. Ciências Humanas & Frederico Westphalen, RS & Pg. 41 - 56 & Set./dez. 2018 \\
\hline \multicolumn{2}{c|}{ Recebido em: 04/01/2019 } & Aceito em: 04/02/2019
\end{tabular}




\section{(1) URI|}

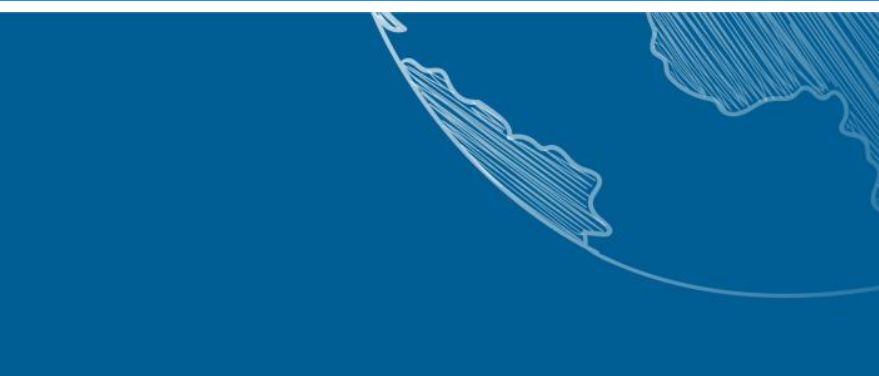

tengan condiciones de llevar innovaciones y tecnologías para el ambiente escolar, objetivando mejoras en la calidad del proceso de enseñanza y de aprendizaje.

Palabras clave: Innovaciones tecnológicas. Enseñanza Híbrida. Sala de clase.

\section{INTRODUÇÃO}

Vivenciamos atualmente, um processo de constantes mudanças e adaptações, estamos diante de uma sociedade amplamente tecnológica, as evoluções são visíveis em todas as áreas e acompanhá-las tornou-se praticamente uma necessidade. Estar por dentro dos acontecimentos e inovações é um desafio, pois informações estão sendo lançadas a todo o momento, e, ao menos um pouco disso precisa estar sob nosso domínio.

Segundo o entendimento de Lévy (1999), o que estamos vivendo, interligados pelas ondas da internet, é a chamada cibercultura, que quer dizer uma nova forma de comunicação suscitada pela interconexão de computadores no mundo todo, não apenas abrangendo a infraestrutura, mas também, o universo informacional que nos abriga.

Partindo para o campo educativo, a inserção de tecnologias e o acompanhamento dos avanços tornam-se aliados no que tange o processo de ensino e aprendizagem. Um exemplo disso é a realidade de alunos e professores, que está extremamente ligada ao uso de algum tipo de tecnologia.

Dessa forma, preparar-se para adentrar no mundo das tecnologias é uma das funções do professor para que possa utilizá-las a seu favor, fazendo delas, ferramentas que auxiliem no processo de ensino e aprendizagem. Porém, é importante que estas não sejam usadas de maneira mecanizada, e sim, que sejam pensadas no sentido de fazer com que os alunos pensem e reflitam durante o processo de aquisição, assimilação e construção de conhecimentos.

Compreendemos que uma das funções da escola é preparar os alunos para viver em sociedade e formar cidadãos que sejam capazes de tomar decisões com autonomia, isso porque apenas ensinar os conteúdos propostos não é o suficiente. É importante que a maneira como ensinamos seja levada em conta, visto que o estudante não pode ser visto como um mero receptor de informações, pois ele precisa ser indagado, 


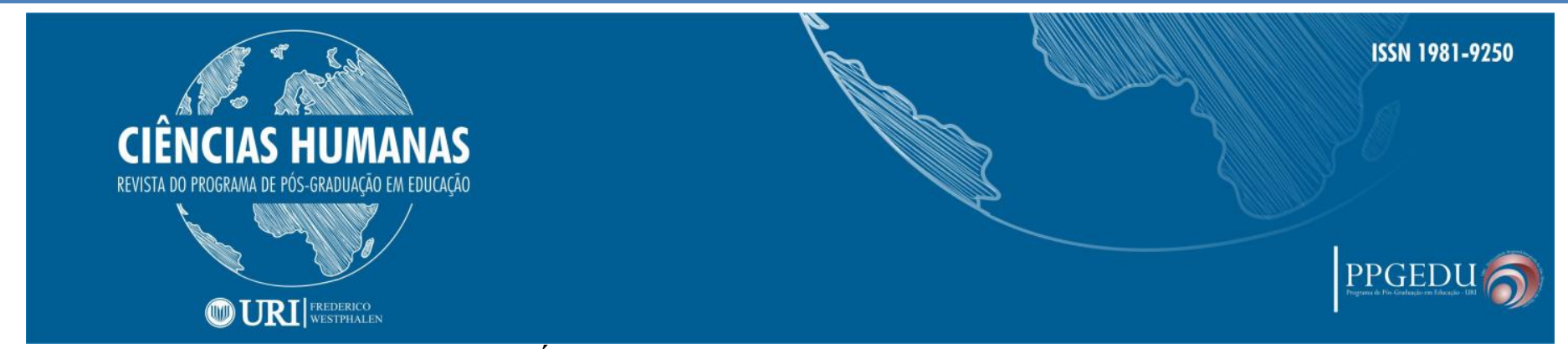

questionado e desafiado. É relevante que o professor trabalhe de um modo que o faça pensar e não agir de forma mecânica.

Nesse sentido, trazemos como possibilidade metodológica o Ensino Híbrido, ressaltando sua particularidades e benefícios, bem como as formas de levá-lo aos poucos para a sala de aula. Pensamos que enquanto metodologia ativa, ele tem um grande potencial para mudar para melhor o cenário educacional.

\title{
TECNOLOGIAS NA EDUCAÇÃO: DESAFIOS E POSSIBILIDADES
}

Sabemos que educar nessa era totalmente tecnológica não é uma tarefa fácil e que isso exige que a formação do professor o prepare para esse contexto da cibercultura. As exigências são muito maiores, visto que as informações estão disponíveis em tempo real e que os estudantes buscam muito mais que uma mera transmissão de conhecimentos na escola. Nesse sentido,

\begin{abstract}
Agora, no início do século XXI, quando tudo é mutável, modificado e mais complexo, necessitamos olhar para trás sem revolta, para ver o que nos serve, descartar aquilo que não funcionou, por mais que alguns sem empenhem em continuar propondo-o e desenvolvendo-o, e construir novas alternativas que beneficiem a formação dos professores e, portanto, a educação promovida por eles. (IMBERNÓN, 2010, p. 24-25)
\end{abstract}

A tecnologia não é propriamente uma metodologia, mas através dela é possível fazer com que uma metodologia seja mais eficaz. Na metodologia do Ensino Híbrido, por exemplo, a tecnologia é uma grande aliada para o crescimento dos estudantes, tanto na construção de conhecimentos, quanto no desenvolvimento de competências e habilidades.

Sabemos que as tecnologias, usadas de qualquer forma não trazem benefícios para o processo de ensino e aprendizagem, elas dão possibilidades ao professor, para que trabalhe de um modo que instigue a criatividade, criticidade e autonomia de seus alunos. Desta forma, é importante considerar que:

\begin{tabular}{c|c|c|c}
\hline Rev. Ciências Humanas & Frederico Westphalen, RS & Pg. $41-56$ & Set./dez. 2018 \\
\hline \multicolumn{2}{c}{ Recebido em: 04/01/2019 } & Aceito em: 04/02/2019 \\
\hline
\end{tabular}




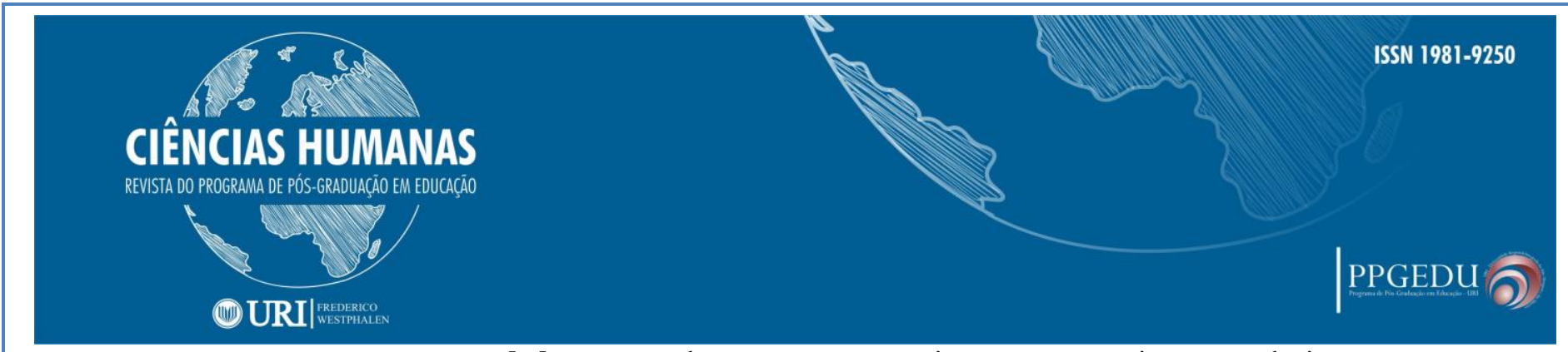

[...] o computador apenas como um instrumento a mais para produzir textos, sons ou imagens sobre suporte fixo (papel, película, fita magnética) equivale a negar sua fecundidade propriamente cultural, ou seja, o aparecimento de novos gêneros ligados à interatividade. $\mathrm{O}$ computador é, portanto, antes de tudo um operador de potencialização da informação (LÉVY, 1996, p. 41).

Então, não adianta ter acesso as tecnologias e continuar com as metodologias tradicionais de transmissão de conhecimentos. Quando se utiliza a tecnologia com o propósito de mudar a aula para melhor, visando que os estudantes participem ativamente e se envolvam nas atividades, o papel do professor é alterado, passando a ser de mediador e orientador, deixando que os alunos tomem decisões e façam descobertas.

A tecnologia surge como uma facilitadora na troca de informações e construção de conhecimentos. Portanto, é recomendável que o profissional docente busque formas de usufruir do melhor que esses recursos têm a nos oferecer. Para isso, é importante que o professor esteja em constante atualização e aperfeiçoamento, através de leituras, formações continuadas, cursos e palestras.

Atitude e coragem são características extremamente relevantes para que o professor comece a inserir as tecnologias da informação e comunicação em suas aulas. A partir do pontapé inicial, o docente passa a descobrir recursos disponíveis no meio virtual que podem tornar as aulas mais dinâmicas, inovadoras e envolventes.

Enquanto mediador e orientador, o professor tem o papel de incentivar que os alunos pensem e expressem suas opiniões com autonomia. Diante disso, o estudante passa a ser protagonista das aulas, mostrando todo o seu potencial e sentindo-se livre para debater, interagir e questionar a qualquer momento.

Desta forma, o aluno passa a ser o centro do processo de ensino e aprendizagem, o que tende a acarretar uma série de benefícios, dentre eles, um melhor rendimento e aproveitamento das aulas, uma troca maior de conhecimentos e experiências e consequentemente, um melhor desempenho e desenvolvimento do estudante, em todos os aspectos, pois:

Os estudantes podem se sentir mais estimulados ao perceber sua progressão constante e sua autonomia sendo alcançada a cada atividade. Eles podem ser desafiados a encontrar soluções para os mais diversos problemas, a trabalhar em grupo, respeitando a individualidade e a capacidade de seus colegas, o

\begin{tabular}{c|c|c|c}
\hline Rev. Ciências Humanas & Frederico Westphalen, RS & Pg. 41 - 56 & Set./dez. 2018 \\
\hline \multicolumn{2}{c|}{ Recebido em: 04/01/2019 } & Aceito em: 04/02/2019 \\
\hline
\end{tabular}




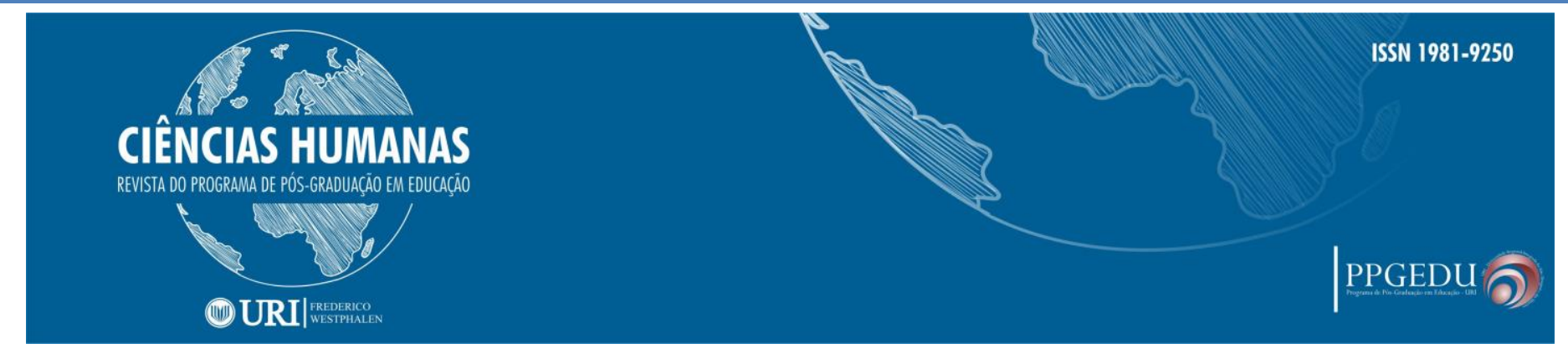

que os preparará para viver em um mundo mais dinâmico e complexo. (SUNAGA; CARVALHO, 2015, p. 142)

A partir desse pressuposto, percebemos que trabalhar desse modo em sala de aula, não é benéfico apenas para o bom andamento e rendimento das aulas, mas também para que os estudantes estejam preparados para viver em sociedade e para enfrentar as mais diversas situações. A tecnologia também oferece recursos que possibilitam personalizar o ensino, conforme explicam Sunaga e Carvalho (2015, p. 143)

\begin{abstract}
Ao contrário da uniformidade do ensino tradicional, cujas aulas e provas são ministradas como se todos tivessem as mesmas habilidades, com as tecnologias digitais pode se personalizar o ensino por meio do uso das plataformas inteligentes, também chamadas de adaptativas. Elas reconhecem as características dos usuários e oferecem atividades em nível personalizado, satisfazendo as necessidades de cada aluno e possibilitando que cada um aprenda no seu tempo, rompendo, assim, o tempo fixo de duração de uma aula, uma característica do ensino brasileiro.
\end{abstract}

Esta é apenas uma das opções que as TDICS podem oferecer. Além destas plataformas que permitem a personalização do ensino, outras possibilidades são: jogos virtuais (previamente selecionados pelo professor), sites educativos, softwares, criação de textos e imagens em diferentes formatos, edição de vídeos e apresentações, ambientes virtuais de aprendizagem, enfim, são diversas alternativas e quanto mais se busca e estuda, mais esse leque se abre. É importante que fique claro que usar a tecnologia sem um propósito e sem que se altere a metodologia não faz sentido, conforme destaca Prensky:

\footnotetext{
A tecnologia não apoia - nem pode apoiar - a velha pedagogia do professor que fala/palestra, exceto em formas mínimas, tais como através da utilização de imagens ou vídeos. $\mathrm{Na}$ verdade, quando os professores usam o velho paradigma de exposição, ao adicionarem a ela a tecnologia, ela com muito mais frequência do que o desejado se torna um empecilho. (2010, p. 202)
}

Então, se não houverem mudanças na maneira de ensinar, há grandes chances de que as tecnologias mais atrapalhem do que auxiliem. Se o professor não estiver disposto a inovar e deixar um pouco de lado o método tradicional, o uso de tecnologias, possivelmente não terá sentido e não trará os resultados esperados, já que se dará a 


\title{
CIÊNCIAS HUMANAS
}

REVISTA DO PROGRAMA DE PÓS-GRADUAĞ̈O EM EDUCAĞ̄o

\section{(1) URI|}

repetição do que já acontecia, apenas com o acréscimo de um recurso tecnológico.

Estamos cientes de que não se pode exigir que o professor utilize as tecnologias, mudando a perspectiva de suas metodologias, se não for lhe dado o suporte necessário, tanto na questão de materiais, estrutura e principalmente no que diz respeito à uma formação continuada de qualidade que lhe mostre os caminhos que pode seguir para iniciar essas mudanças. Nesse sentido, Levy (2011) afirma que é fundamental formar continuamente os professores para atuar nesta realidade que tem a tecnologia como mediadora do processo de ensino e aprendizagem. Como complemento, Silva (2008, p. 35) ressalta que:

\begin{abstract}
A incorporação de novas tecnologias à escola exige que professor e aluno saibam o que fazer com elas, para que adquiram sentido nas práticas realizadas em aula e possam efetivamente contribuir para que a aprendizagem, isso porque a maioria das tecnologias educacionais não garante a atividade do aluno. Assim, o que pode parecer novo, na verdade, representa um retorno ao método tradicional, condenado por inúmeras razões, uma delas a passividade do aluno, tratado como receptor, tábula rasa.
\end{abstract}

Justamente com o propósito de que o professor saiba como agir diante das tecnologias é que a formação precisa levar em conta esses aspectos, seja ela inicial ou continuada. É relevante que professores e futuros professores sejam instruídos sobre as possibilidades e potencialidades da utilização das tecnologias da informação e comunicação, para que se encorajem a lançar mão de recursos que possam fazer com que suas aulas melhorem em termos de aprendizagem, tornando-as mais dinâmicas, atrativas e produtivas.

No entendimento de Garcia (2007), para educar na era do conhecimento é necessária uma nova ideia da mente. Uma concepção que entenda a mente como um sistema que se autorregula e organiza a partir de múltiplas conexões. Assim, é importante pensarmos na formação de uma maneira mais aberta, que se adapte às necessidades dos indivíduos e que permita não apenas aprender a ensinar, mas sim gerar conhecimento e inovação sobre o ensino.

Sabemos que inovar em sala de aula não é uma tarefa fácil e que isso exige que o professor esteja verdadeiramente comprometido com a causa. Iniciando por pequenas 


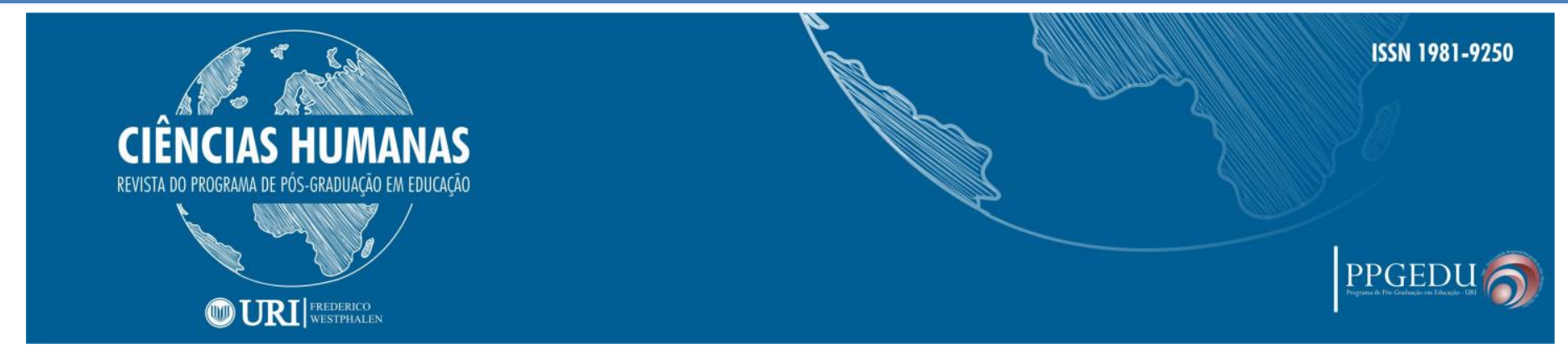

práticas, como trabalhos de pesquisa, o educador vai acostumando-se com esse mundo e irá se sentindo mais à vontade para propor novas atividades com o auxílio de tecnologias. Nóvoa (1995, p. 28) aborda de maneira significativa a inovação das práticas educativas:

É preciso trabalhar no sentido da diversificação dos modelos e das práticas de formação, instituindo novas relações dos professores com o saber pedagógico e científico. A formação passa pela experimentação, pela inovação, pelo ensaio de novos modos de trabalho pedagógico. E por uma reflexão crítica sobre a sua utilização. A formação passa por processos de investigação diretamente articulados com as práticas educativas.

Portanto, é recomendado por grande parte dos autores educacionais que o profissional docente não pare no tempo, incentivando que ele se adapte a novas metodologias, às inovações tecnológicas e aprenda a trabalhar com elas. É relevante que o professor esteja disposto a aprender sempre, tendo em mente que sua identidade profissional se forma a cada dia, a cada nova experiência, a cada aula e a cada curso. Enfim, ela está em constante transformação visando sempre o aprendizado dos seus alunos.

\section{ENSINO HÍBRIDO: UMA POSSIBILIDADE METODOLÓGICA}

O Ensino Híbrido constitui-se em "uma tentativa de oferecer “- o melhor de dois mundos" - isto é, as vantagens da educação online combinadas com todos os benefícios da sala de aula tradicional.” (CHRISTENSEN; HORN; STAKER, 2013, p. 3)

O tradicional não é abandonado ou simplesmente deixado para trás, o ensino híbrido, também chamado de blended learning:

[...] é um programa de educação formal no qual um aluno aprende, pelo menos em parte, por meio do ensino online, com algum elemento de controle do estudante sobre o tempo, lugar, modo e/ou ritmo do estudo, e pelo menos em parte em uma localidade física supervisionada, fora de sua residência. (CHRISTENSEN; HORN; STAKER, 2013, p. 7)

Essa proposta respeita o ritmo de aprendizagem de cada estudante e busca a personalização das ações de ensino e aprendizagem, visto que através dele é possível 


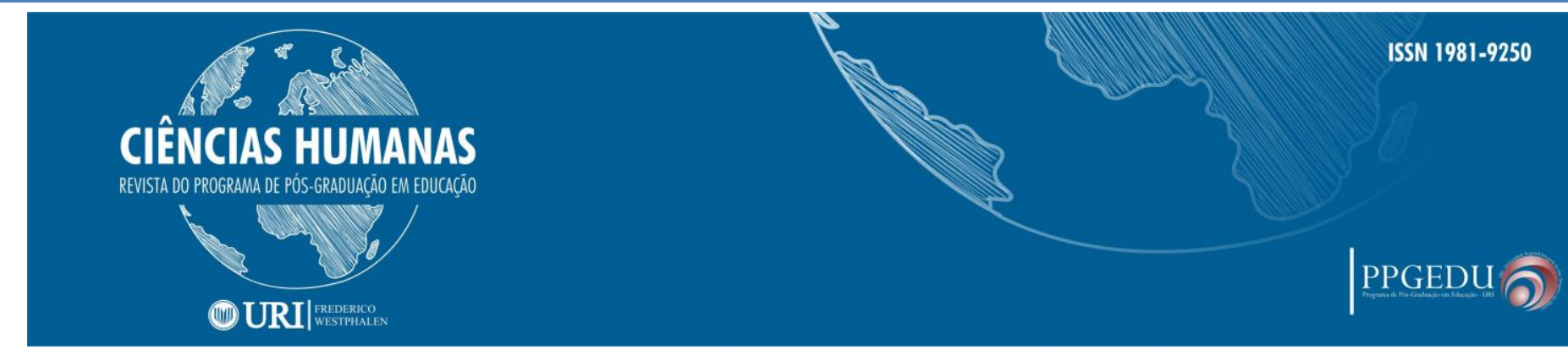

identificar o modo como cada um aprende e intervir de forma mais efetiva de acordo com essas informações. Como as atividades não precisam ser iguais em todos os momentos, o professor consegue perceber quando os alunos estão ou não avançando em determinado conteúdo podendo elaborar alguma forma de revisão ou atividades mais avançadas, dependendo do rendimento e aprendizado de cada aluno. Nesse sentido, é necessário criar:

[...] uma solução híbrida que dê aos educadores o melhor dos dois mundos isto é, as vantagens do ensino on-line combinados com todos os benefícios da sala de aula tradicional. A opção disruptiva é empregar o ensino on-line em novos modelos que se afastem da sala de aula tradicional e foquem inicialmente nos não consumidores que valorizam a tecnologia pelo que ela é mais adaptável, acessível e conveniente. (CHRISTENSEN, HORN; STAKER, 2013, p. 15)

Deve-se sempre ter em mente que trabalhar com tecnologias digitais sem uma intencionalidade pedagógica e sem explorá-las ao ponto de maximizar os conhecimentos e desenvolver habilidades nos estudantes não faz sentido. O professor precisa ter segurança e firmeza ao levar essa proposta para a sala de aula e usá-lo com muita criatividade, conforme ressaltam Bacich, Tanzi Neto e Trevisani.

\begin{abstract}
A integração das tecnologias digitais na educação precisa ser feita de modo criativo e crítico, buscando desenvolver a autonomia e a reflexão dos seus envolvidos, para que eles não sejam apenas receptores de informações. $O$ projeto político-pedagógico da escola que queira abarcar essas questões precisa ponderar como fazer essa integração das tecnologias digitais para que os alunos possam aprender significativamente em um novo ambiente, que agora contempla o presencial e o digital. (2015, p. 47)
\end{abstract}

Os alunos já estão acostumados com esse mundo e devem ser desafiados pelo professor, que precisa habituar-se ao meio tecnológico e adequar seu plano de aula.

Não há obstáculos. Todos os estudantes têm uma habilidade extraordinária para usar esse tipo de ferramenta. Agora, os professores têm que conhecer tão bem quanto as crianças. Sobretudo, isso tem que ser utilizado numa ótica de aprendizagem colaborativa. Eu acredito que o professor precisa se capacitar, porque ele só pode ensinar tudo o que domina. Eu não acredito na formação do professor apenas para usar as redes sociais. O professor também tem que se esforçar. Utilizar isso para si próprio. É só uma questão de entrar nessa cultura. (MESQUITA, 2013, p. 1)

\begin{tabular}{c|c|c|c}
\hline Rev. Ciências Humanas & Frederico Westphalen, RS & Pg. $41-56$ & Set./dez. 2018 \\
\hline \multicolumn{2}{c}{ Recebido em: 04/01/2019 } & Aceito em: 04/02/2019 \\
\hline
\end{tabular}


Antes de tudo, o professor necessita estar disposto a inovar e aberto a mudanças, em seguida deve conhecer e dominar as tecnologias, buscando capacitações e cursos de formação que o prepare para utilizar das tecnologias com segurança. A partir daí, o profissional se desafia e adentra no mundo tecnológico, inovando suas metodologias e fortalecendo o aprendizado dos seus alunos. Nesse sentido, a sala de aula também pode ser reorganizada:

Se eu considero que as crianças são os verdadeiros protagonistas da sua aprendizagem, que aprendem a partir da manipulação e da experimentação ativa da realidade e por meio das descobertas pessoais; se, além disso, entendo que "os outros" também são uma fonte importante de conhecimento, tudo isso terá reflexos na organização de minha sala de aula: tendo espaços para o trabalho em pequenos grupos, distribuindo o mobiliário e os materiais para que as crianças tenham autonomia e "enchendo" o espaço de materiais que despertem o interesse infantil para manipular, experimentar e descobrir. (ZABALZA, 1998, p. 249)

Conhecendo seus alunos, o modo como cada um aprende e inserindo as tecnologias digitais em sua prática, o professor precisa pensar como a sala de aula precisa ser organizada para obter melhores resultados no processo de ensino e aprendizagem. Para que as coisas deem certo e o ensino tenha mais qualidade, o apoio da escola é essencial, pois "o espaço físico deve estar em sintonia com as aulas híbridas no contexto da adequação dos conteúdos e na facilidade de acesso aos materiais." (NASCIMENTO, 2015, p. 121)

[...] não podemos estar na nossa sala de aula como quem está em uma casa alugada na qual nada pode ser modificado. Muito pelo contrário, a sala de aula é um dos principais instrumentos com os quais contamos para desempenhar a nossa tarefa de educadores (as). (ZABALZA, 1987, p. 122)

É de responsabilidade do professor ver a sala de aula como um espaço diferenciado de aprendizagem. A sala de aula tradicional, com carteiras alinhadas já está ultrapassada e não estimula a aprendizagem dos estudantes. Em alguns momentos as carteiras podem estar alinhadas, porém o movimento do mobiliário e dos estudantes é necessário para que o ensino ganhe vida e significado. 


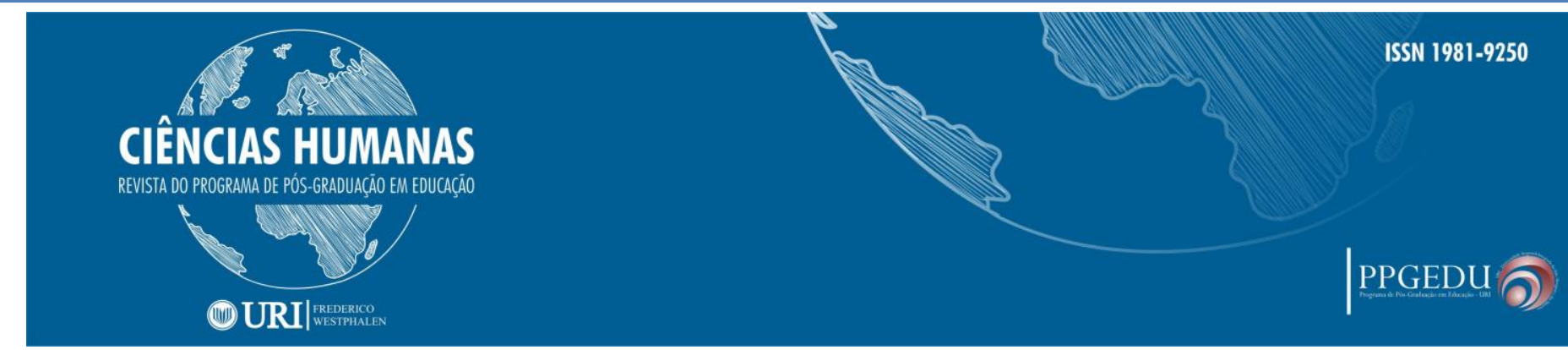

Com professores comprometidos e dispostos a inovar, alunos com sede de aprender de maneiras diferentes, pais incentivadores e uma gestão que prime por um ensino de qualidade o Ensino Híbrido tende a se concretizar em uma excelente alternativa de tornar a escola um espaço mais amplo e atual de aprendizagem. Assim,

O ensino híbrido vem ao encontro das necessidades recentes de descobrir a melhor prática educativa para professores e escolas. Trata-se de um modelo de ensino que pressupõe o uso da tecnologia para o desenvolvimento das atividades dentro e fora da classe, em que o aluno é estimulado a buscar o conhecimento com a mediação do professor e da escola. (SILVA; CAMARGO, 2015, p. 181)

O aluno deixa de ser um mero receptor de informações e conteúdos e passa a participar ativamente do processo de ensino e aprendizagem, desenvolvendo sua criatividade, criticidade e autonomia. Porém,

A preocupação e a necessidade de elevar o nível de personalização e de autonomia dos alunos, bem como de mudar o formato das aulas e o uso dos seus conteúdos disciplinares, são discussões anteriores ao advento desse tipo de modelo de ensino. Contudo, o caráter inovador do blended potencializa os resultados e permite uma melhor avaliação do professor sobre a real situação de aprendizagem do aluno e dos caminhos a serem seguidos, respeitando o ritmo, as habilidades e as competências dos estudantes em cada disciplina. (SILVA; CAMARGO, 2015. p. 183)

Por meio do Ensino Híbrido o aluno é motivado a participar mais ativamente das aulas, interagindo e fazendo associações com as suas vivências. $\mathrm{O}$ desafio da escola é grande e a equipe de professores precisa estar empenhada em auxiliar os estudantes para que tenham um futuro próspero e estejam preparados para enfrentar a vida em todos os seus sentidos. Para isso:

As metodologias precisam acompanhar os objetivos pretendidos. Se queremos que os alunos sejam proativos, precisamos adotar metodologias nas quais eles se envolvam em atividades cada vez mais complexas, em que tenham de tomar decisões e avaliar os resultados, com apoio de materiais relevantes. Se queremos que sejam criativos, eles precisam experimentar inúmeras novas possibilidades de mostrar sua iniciativa. (MORAN, 2015, p. 34)

\begin{tabular}{c|c|c|c}
\hline Rev. Ciências Humanas & Frederico Westphalen, RS & Pg. $41-56$ & Set./dez. 2018 \\
\hline \multicolumn{2}{c}{ Recebido em: 04/01/2019 } & Aceito em: 04/02/2019 \\
\hline
\end{tabular}




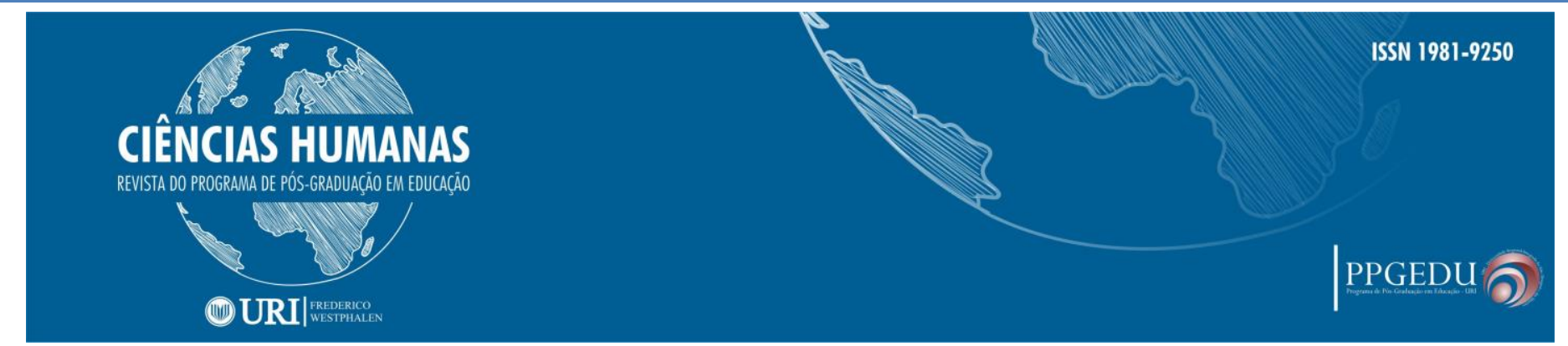

Dessa forma, o professor deve propor atividades desafiadoras aos estudantes para que os mesmos exercitem sua criatividade e desenvolvam diferentes habilidades e competências. O trabalho com tecnologias vem de encontro a isso e mune o professor com diferentes alternativas para dar mais dinamicidade às suas aulas. Vivemos em uma era de mudanças, onde inovações surgem todos os dias e os alunos devem ser formados de acordo com a realidade social em que estão inseridos. Trazemos na sequência uma síntese dos modelos de Ensino Híbrido, ressaltando as características de cada um e de que forma eles podem contribuir para a aprendizagem dos estudantes.

\section{Modelos de Ensino Híbrido}

O Ensino Híbrido, ao possibilitar a integração de momentos presenciais e online e a personalização, pode acontecer por meio do modelo de rotação, modelo flex, à la carte e virtual enriquecido. No modelo de rotação, há uma alternância de atividades que oferecem diferentes experiências de aprendizagem aos estudantes. Esse modelo é dividido em quatro propostas, sendo elas a rotação por estações, o laboratório rotacional, a sala de aula invertida e a rotação individual. Na rotação por estações,

\footnotetext{
Os estudantes são organizados em grupos, cada um dos quais realiza uma tarefa, de acordo com os objetivos do professor para a aula em questão. Podem ser realizadas atividades escritas, leituras, entre outras. Um dos grupos estará envolvido com propostas on-line que, de certa forma, independem do acompanhamento direto do professor. [...] Em um dos grupos, o professor pode estar presente de forma mais próxima, garantindo o acompanhamento de estudantes que precisam de mais atenção. [...] Após um determinado tempo, previamente combinado com os estudantes, eles trocam de grupo, e esse revezamento continua até todos terem passado por todos os grupos. (BACICH; TANZI NETO; TREVISANI, 2015, p. 55)
}

As atividades devem ser planejadas sem que precisem respeitar uma sequência, para que todos os alunos participem de todas as atividades independentemente da realizada anteriormente. Dessa maneira o professor também percebe em qual atividade cada aluno se destaca e de que modo o aprendizado é potencializado.

No laboratório rotacional: 


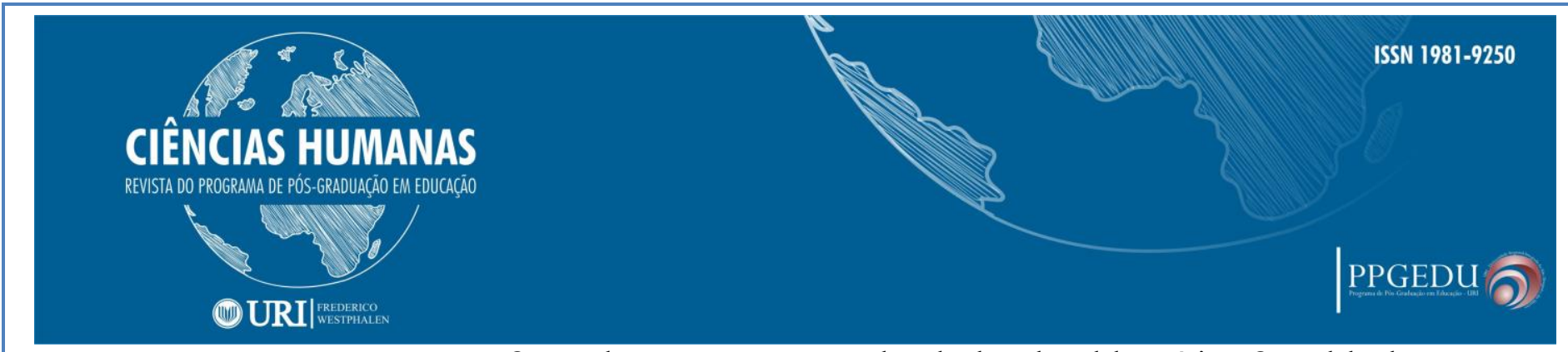

Os estudantes usam o espaço da sala de aula e laboratórios. O modelo de laboratório rotacional começa com a sala de aula tradicional, em seguida adiciona uma rotação para computador ou laboratório de ensino. Os laboratórios rotacionais frequentemente aumentam a eficiência operacional e facilitam o aprendizado personalizado, mas não substituem o foco nas lições tradicionais em sala de aula. (BACICH; TANZI NETO; TREVISANI, 2015, p. 55)

O laboratório rotacional, em alguns aspectos, poderia ser um caminho para inserir no mundo da tecnologia professores que não abrem mão do método tradicional. A quebra de paradigma não é tão impactante, visto que os docentes poderão conservar o método que utilizavam e buscar a inovação em outro momento da aula a fim de complementar o conteúdo e reforçar a compreensão do mesmo. Essa proposta é melhor aplicada em escolas que dispõem de laboratório de informática ou de ensino, ou ainda, pode ser realizada em um local próximo à escola que possa ceder o espaço em alguns momentos. Em escolas que contam com dispositivos móveis, como tablets e notebooks, a proposta pode ser realizada organizando dois espaços: um para os alunos trabalharem individualmente e online e, outro, para a atuação do professor com metade da turma.

Quando nos reportamos a sala de aula invertida:

\begin{abstract}
A teoria é estudada em casa, no formato on-line, e o espaço da sala de aula é utilizado para discussões, resolução de atividades, entre outras propostas. $\mathrm{O}$ que era feito em classe (explicação do conteúdo) agora é feito em casa, e o que era feito em casa (aplicação, atividades sobre o conteúdo) agora é feito em sala de aula. (BACICH; TANZI NETO; TREVISANI, 2015, p. 56)
\end{abstract}

Essa proposta pode proporcionar uma troca muito rica de experiências e conhecimentos, levando em conta o que o aluno aprendeu sozinho e o que é compartilhado com a turma e professor em sala de aula, além do desenvolvimento da autonomia, criatividade e criticidade, que são essenciais para o enfrentamento de situações cotidianas e superação de obstáculos. Quanto à rotação individual,

Cada aluno tem uma lista das propostas que deve contemplar em sua rotina para cumprir os temas a serem estudados. Aspectos como avaliar para personalizar devem estar muito presentes nessa proposta, uma vez que a elaboração de um plano de rotação individual só faz sentido se tiver como foco o caminho a ser percorrido pelo estudante de acordo com suas 


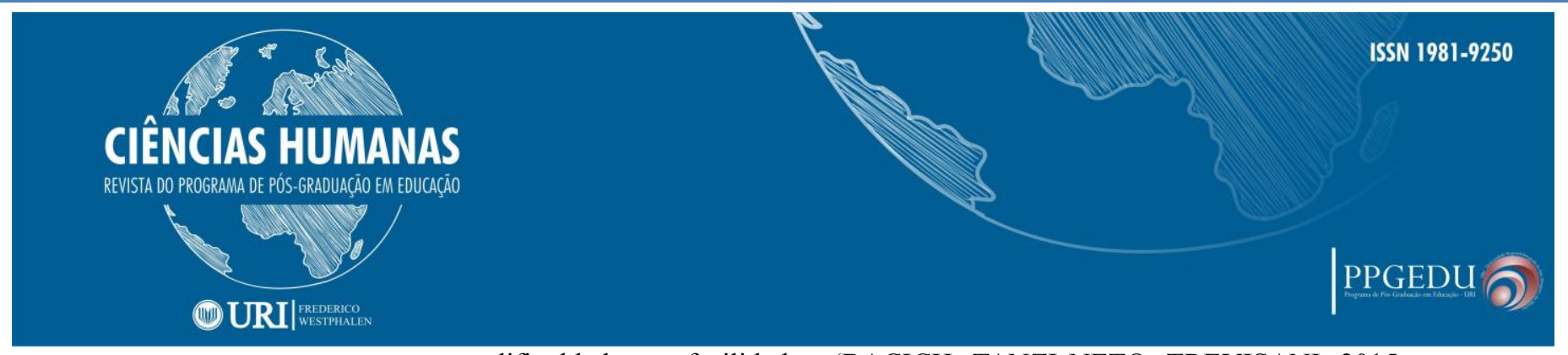

dificuldades ou facilidades. (BACICH; TANZI NETO; TREVISANI, 2015, p. 56-57)

Conforme abordado pelos autores, a rotação individual pode ser utilizada com o intuito de identificar as facilidades e dificuldades de cada aluno e, também, para ofertar experiências de aprendizagem que podem ser realizadas no tempo, ritmo e necessidade do aluno, favorecendo a personalização e o trabalho colaborativo.

Já na abordagem "flex", os autores ressaltam que:

Os alunos também têm uma lista a ser cumprida, com ênfase no ensino online. O ritmo de cada estudante é personalizado, e o professor fica à disposição para esclarecer dúvidas. Esse modelo, apesar de ser considerado uma possibilidade metodológica, é tido como disruptivo e propõe uma organização de escola que não é comum no Brasil. (BACICH; NETO; TANZI TREVISANI, 2015, p. 58)

Podemos salientar que este assemelha-se à rotação individual, porém os alunos não são organizados por séries, sendo que os projetos podem ser realizados entre alunos de séries diferentes. A estrutura das escolas em nosso país não suporta uma mudança como esta e iniciar por esse modelo seria algo muito radical tanto para professores como para alunos. Por esse motivo, é considerado um modelo disruptivo (CHRISTENSEN, HORN, STAKER, 2013), ao romper com o modelo educacional vigente.

No modelo à la carte:

O estudante é responsável pela organização de seus estudos, de acordo com os objetivos gerais a serem atingidos, organizados em parceria com o educador; a aprendizagem, que pode ocorrer no momento e local mais adequados, é personalizada. Nessa abordagem, pelo menos um curso é feito inteiramente on-line, apesar do suporte e da organização compartilhada com o professor. A parte on-line pode ocorrer na escola, em casa ou em outros locais. (BACICH; TANZI NETO; TREVISANI, 2015, p. 58)

Já o virtual enriquecido,

Trata-se de uma experiência realizada por toda a escola, em que em cada disciplina (como a de matemática, por exemplo), os alunos dividem seu tempo entre a aprendizagem on-line e a presencial. Os estudantes podem se apresentar, presencialmente, na escola, apenas uma vez por semana. (BACICH; TANZI NETO; TREVISANI, 2015, p. 58)

\begin{tabular}{c|c|c|c}
\hline Rev. Ciências Humanas & Frederico Westphalen, RS & Pg. $41-56$ & Set./dez. 2018 \\
\hline \multicolumn{2}{c}{ Recebido em: 04/01/2019 } & Aceito em: 04/02/2019 \\
\hline
\end{tabular}


Esse modelo é utilizado nas universidades que oferecem cursos à distância, onde a maioria das atividades são realizadas virtualmente e os estudantes têm aulas presenciais uma vez por semana. Na escola básica implementar os modelos à la carte e virtual enriquecido é um desafio e não é regulamentado em nosso país.

Esses modelos não são sequenciais e cabe à escola e professores analisar qual deles abrigará os objetivos propostos. Também não é obrigatório que se opte por um deles, os mesmos podem ser utilizados de modo integrado permitindo uma flexibilidade no planejamento. Assim, "a escola pode transformar-se em um conjunto de espaços ricos em aprendizagem significativas, presenciais e digitais, que motivem os alunos a aprender ativamente, a pesquisar o tempo todo, a serem proativos, a saber tomar iniciativas e interagir." (MORAN; MASETTO; BEHRENS, 2013, p. 31)

\section{CONCLUSÃO}

Com todas as mudanças e inovações tecnológicas que nos acercam torna-se impraticável permanecermos com as mesmas metodologias, os mesmos recursos e as mesmas aulas. Com a geração de alunos que temos nas escolas, inovar tornou-se uma necessidade e o cotidiano escolar precisa ser repensado. A informação disponível em tempo real exige que a escola evolua em vários aspectos.

Sabemos que o desafio é grande tanto para professores quanto para a gestão e para a comunidade escolar como um todo. Mudar sempre gera desconforto, assusta, mas muitas vezes é imprescindível. Os profissionais precisam abandonar certas crenças, desconstruir teorias e ver no novo uma possibilidade de tornar os alunos mais autônomos, criativos e críticos fazendo com que ele deixe de ser um mero expectador.

É importante que os estudantes se sintam parte do processo de ensinar e aprender, sendo protagonistas, tornando-se alunos mais independentes, desenvolvendo a capacidade de buscar, pensar, questionar e refletir sobre os conteúdos escolares. O uso de tecnologias pode ser um meio de transformar esse cenário e o Ensino Híbrido pode ser uma das soluções para algumas das deficiências presentes no âmbito escolar. 


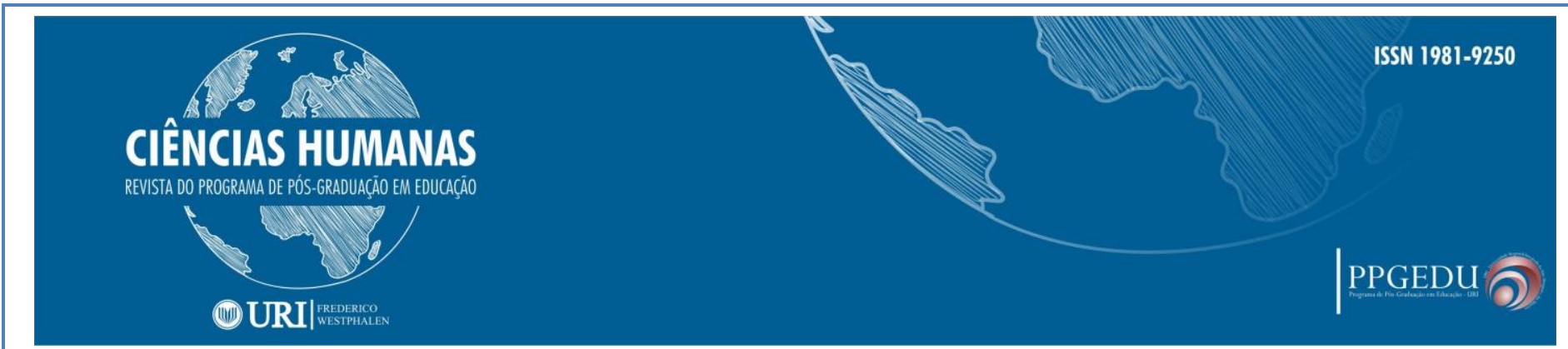

Nessa busca infatigável por fazer com que as aulas sejam mais dinâmicas, significativas, interativas e produtivas, trouxemos neste artigo o Ensino Híbrido como uma das possíveis soluções, que se bem pensado e utilizado pelo professor pode trazer inúmeros benefícios para o cenário educacional.

\section{REFERÊNCIAS BIBLIOGRÁFICAS}

BACICH, Lilian; TANZI NETO, Adolfo; TREVISANI, Fernando de Mello (Orgs.). Ensino híbrido: personalização e tecnologia na educação. Porto Alegre: Penso, 2015.

CRISTENSEN, M.; HORN, M.; STAKER, H. Ensino híbrido: uma inovação disruptiva. Uma introdução à teoria dos híbridos. Instituto Península (Trad.). Fundação Lemann. Porto Alegre: Penso, 2013.

GARCIA, Carlos Marcelo. La formación docente en la sociedade del conocimiento y la información: avances y temas pendientes. Olhar de Professor, Ponta Grossa, v. 10, n. 1, p. 63-90, 2007.

IMBERNÓN, Francisco. Formação continuada de professores. Porto Alegre: Artmed, 2010.

LÉVY, P. A. O que é virtual. Tradução de Paulo Neves. São Paulo: Ed. 34, p. 160, 2011.

LÉVY, Pierre. Cibercultura. Rio de Janeiro: Editora 34, Paulus, 1999.

MESQUITA, D. Internet e escola de mãos dadas. Revista Gestão Educacional, abr. 2013. Disponível em:

$<$ http://www.gestaoeducacional.com.br/index.php/reportagens/entrevistas/115-internete-escola-de-maos-dadas>. Acesso em: 26 out. 2016.

MORAN, J. M.; MASETTO, M. T.; BEHRENS, M. A. Novas tecnologias e mediação pedagógica. Rev. Atual, 21 ed. Campinas: Papirus, 2013.

MORAN, José. Educação Híbrida: um conceito-chave para a educação, hoje. In:

BACICH, Lilian; TANZI NETO, Adolfo; TREVISANI, Fernando de Mello (Orgs.).

Ensino híbrido: personalização e tecnologia na educação. Porto Alegre: Penso, 2015.

NASCIMENTO, Maria Alessandra Dubowski Nascimento. A experiência da Escola Municipal Prof ${ }^{a}$ Coraly de Souza Freire. In: BACICH, Lilian; TANZI NETO, Adolfo; TREVISANI, Fernando de Mello (Orgs.). Ensino híbrido: personalização e tecnologia na educação. Porto Alegre: Penso, 2015. 


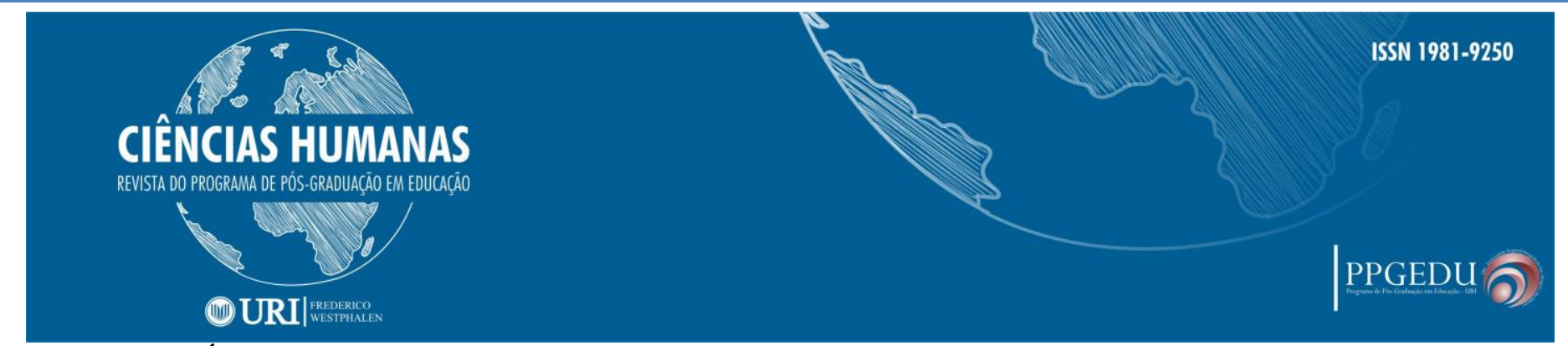

NÓVOA, A. Os professores e sua formação. Lisboa - Portugal: Dom Quixote, 1995.

PRENSKY, Marc. O papel da tecnologia no ensino e na sala de aula. Conjectura, v. 15, n. 2, maio/ago. 2010.

SILVA, Kátia Regina Xavier. Criatividade e inclusão na formação de professores: Representações e Práticas Sociais. Rio de Janeiro: UFRJ, 2008.

SILVA, Rodrigo Abrantes da; CAMARGO, Ailton Luiz. A cultura escolar na era digital. In: BACICH, Lilian; TANZI NETO, Adolfo; TREVISANI, Fernando de Mello (Orgs.). Ensino híbrido: personalização e tecnologia na educação. Porto Alegre: Penso, 2015.

SUNAGA, Alexsandro; CARVALHO, Camila Sanches de. As tecnologias digitais no ensino híbrido. In: BACICH, Lilian; TANZI NETO, Adolfo; TREVISANI, Fernando de Mello (Orgs.). Ensino híbrido: personalização e tecnologia na educação. Porto Alegre: Penso, 2015.

ZABALZA, M. A. Didáctica de la educación infantil. Madrid: Narcea, 1987.

ZABALZA, M. A. Qualidade em educação infantil. Porto Alegre: Artmed, 1998. 